\title{
Growth differentiation Factor 11 is an encephalic regionalizing factor in neural differentiated mouse embryonic stem cells
}

Nele Vanbekbergen ${ }^{1+}$, Marijke Hendrickx ${ }^{1,2+}$ and Luc Leyns ${ }^{1 *}$

\begin{abstract}
Background: The central nervous system has a complex structural organization and consists of different subdomains along the antero-posterior axis. However, questions remain about the molecular mechanisms leading to the regionalization of this organ. We used a previously developed methodology to identify the novel patterning role of GDF11, a TGF- $\beta$ signaling factor.

Findings: Using an assay based on neural differentiated mouse embryonic stem cells, GDF11 is shown to induce diencephalic (posterior forebrain), mesencephalic (midbrain) and metencephalic (anterior hindbrain) fates at the expense of telencephalic (anterior forebrain) specification. GDF11 has not previously been implicated in the early patterning of the nervous system. In addition, inhibition of the TGF- $\beta$ type I receptors Alk4, Alk5 and Alk7 by the pharmacological inhibitor SB431542 caused a strong anteriorization of the cells.

Conclusions: Our findings suggest that GDF11 is involved in the earliest steps of the brain patterning during neurogenesis in the vertebrate embryo and is shown to be a regionalizing factor of the regional fate in the developing brain. This regionalization is not a typical posteriorizing signal as seen with retinoic acid, FGF or BMP molecules. To our knowledge, this is the first time that GDF11 is implicated in the earliest steps of the patterning of the neural plate.
\end{abstract}

Keywords: Mouse ES cells, Brain patterning, GDF11

\section{Introduction}

Neural development is comprised of various processes that generate and form the nervous system during the earliest stages of embryogenesis. During early vertebrate development, the central nervous system (CNS) is subdivided along the antero-posterior (A/P) axis into forebrain, midbrain, hindbrain and spinal cord. Classical experiments in Amphibia suggest the existence of a two-step mechanism for this early organization. The neurectodermal tissue that is formed during the process of neural induction is initially anterior in character. It becomes secondarily posteriorized by a series of posteriorizing, or 'transforming' factors to obtain the full range of regional subtypes of the CNS along the $A / P$ axis [1-3]. Several posteriorizing factors have been

\footnotetext{
*Correspondence: Ileyns@vub.ac.be

${ }^{\dagger}$ Equal contributors

'Department of Biology, Lab for Cell Genetics, Vrije Universiteit Brussel (VUB), 2 Pleinlaan, B-1050 Brussels, Belgium

Full list of author information is available at the end of the article
}

identified in amphibian embryos, such as Fgfs and Wnts [4-8]. Nevertheless, how the regionalization of the neural plate occurs in early mouse embryogenesis remains elusive.

An important tool to study embryonic development is mouse embryonic stem cells $(\mathrm{mESc})$. mESc are derived from the inner cell mass (ICM) of a pre-implantation blastocyst stage embryo and have the capacity to self-renew unlimitedly in vitro in an undifferentiated state. Furthermore, they can be differentiated in vitro and in vivo into all cell types of the adult body $[9,10]$. The parallelism between the differentiating embryo and the in vitro differentiation of $\mathrm{mESc}$ makes them an important tool to study embryonic development.

In a previous study [11], we developed a methodology to study mammalian early neural patterning which is based on the neural differentiation method of mESc as described by Ying and colleagues [12]. It involves the neural differentiation of mESc in the specialized serum-free N2B27 medium system in adherent cultures to obtain neural 
precursor cells. Subsequently the neural precursors were treated with potential posteriorizing factors $[11,12]$. However, because many of the putative patterning factors (e.g. Bmp4, Wnt3a) were inhibitory to neural induction and some even had an effect on mESc self-renewal [13-18], we designed an experimental set-up that separated the neural induction from the neural patterning step, in order to avoid these negative effects on neural differentiation.

The signalling by the Transforming Growth Factor $\beta$ (TGF- $\beta$ ) superfamily signalling is essential during a diverse set of cellular processes, including differentiation, patterning, proliferation, specification of developmental fate during embryogenesis as well as in mature tissue [19-21]. Members of the TGF- $\beta$ superfamily include activins, inhibins, Bone Morphogenic Proteins (BMPs) and Growth of Differentiation Factors (GDFs). TGF- $\beta$ factors initiate signalling by binding a heterodimeric complex of serine/threonine kinase transmembrane receptors, type I and type II [19-21]. The ligand first binds to the extracellular domain and activates a type II receptor homodimer, resulting in phosphorylation of a type I receptor homodimer. Once activated, the type I receptor directly phosphorylates and activates downstream a set of Smad proteins and initiates the intracellular signalling cascade. Type II receptors include BMPRII, ActRIIA, ActRIIB and T- $\beta$-RII. Type I receptors include seven members, activin-like kinases (ALK 1-7) [20,22]. There are eight distinct Smad proteins: the receptor-regulated Smads, which include Smad1, 2, 3, 5 and 8; the Co-mediator Smad, Smad4 and the inhibitory Smads, which include Smad6 and 7 [19].

One of the members of the TGF- $\beta$ superfamily, Growth of Differentiation Factor 11 (GDF11), also known as BMP11, has been shown to regulate anterior-posterior patterning of the body axis, kidney development and closure of the palate [23-27].

In the animal cap assay (AC) in Xenopus, GDF11 induces axial mesoderm and at higher concentrations also neural tissue, an activity that can be inhibited by Follistatin (Fst), indicating that in the AC assay, GDF11 has an effect similar to that of Activin [25]. In the mouse, GDF11 has been implicated in the establishment of the skeletal pattern. Mice that are mutant for this gene die within 24 hours after birth. They show homeotic anterior transformations of the vertebrae, mainly in the lumbar and the thoracic regions and a posterior displacement of the hindlimbs [27]. GDF11 regulates the patterning of the vertebrae by controlling the expression of the Hox genes, as the expression domain of several Hox genes is shifted in the mutants. In the chicken, it was shown that GDF11 not only causes a shift in the expression of Hox genes, but also causes a rostral shift in the position of the motor neuron columns and pools [28]. However, in the mouse embryo, it is not clear whether GDF11 has a patterning effect on other tissues than skeletal ones. In the mouse embryo, GDF11 is expressed first faintly in the posterior half of the $7.5 \mathrm{dpc}$ embryo where expression is observed in the primitive streak in the ingressing cells forming the mesoderm. At about $8.5 \mathrm{dpc}$, GDF11 is expressed posteriorly; in the most anterior regions of the neural epithelium, and in both the neural epithelium and the mesoderm in more posterior regions. At $9.0 \mathrm{dpc}$, GDF11 continues to be expressed in the former primitive streak region, and by $9.5 \mathrm{dpc}$, the expression is restricted mainly to the tail bud, but is also found in the posterior dorsal neural tube $[27,29]$. It was reported that GDF11 mRNA can also be detected in the encephalic region of 9.5 $\mathrm{dpc}$ and $10.5 \mathrm{dpc}$ embryos [30]. These findings are consistent with a more general role of GDF11 during neural differentiation and expression in diverse neural tissues, which include developing spinal cord, dorsal root ganglia and embryonic and postnatal brain.

Based on this expression data and its skeletal patterning role, we hypothesized that GDF11 was a potential patterning factor that could be involved in the early neural $\mathrm{A} / \mathrm{P}$ patterning of the mouse embryo. Therefore, in this study, we investigated whether GDF11 has a direct role in the early regional identity of neural progenitor cells and whether this factor can posteriorize freshly induced neural progenitors that are initially anterior in character. The potential neural patterning effect of GDF11 was assessed in our ES cell based patterning system. Our data suggest GDF11 is an encephalic regionalizing factor during early neural patterning in the vertebrate embryo.

\section{Research methods}

\section{Mouse ESC cultures and differentiation}

Mouse E14Tg2a feeder free ES cells were cultured in Knock Out DMEM (Gibco, Carlsbad, CA) supplemented with $10 \%$ fetal calf serum (Hyclone, Logan, UT), $0.1 \mathrm{mM} \beta$ mercaptoethanol (GIBCO), 1\% non-essential amino acids (GIBCO), 2 mM L-glutamine (Sigma, St. Louis, MO), antibiotics (Sigma) and $1000 \mathrm{U} / \mathrm{ml}$ LIF (Sigma), on dishes coated with $0.1 \%$ gelatin.

For the patterning experiments, cells were cultured for 48 hours in N2B27 as described by Ying et al. [18] at a density of 7500 cells per $\mathrm{cm}^{2}$. Subsequently, the medium was replaced with N2B27 containing human recombinant GDF11 (R\&D systems, Minneapolis, MN) and the TGF- $\beta$ type I receptor inhibitor SB-431542 (Sigma). Culture occurred for another 4 days, refreshing the medium every 2 days.

To confirm the activity of the tested growth factors, cells were cultured similarly for 48 hours and collected 3 hours after treatment with the specific factor, and expression levels of known target genes were assessed. Three independent experiments were performed.

\section{Quantitative reverse transcription (qRT-PCR)}

RNA was extracted from the collected cell samples using the SV Total RNA Isolation System kit (Promega, Madison, 

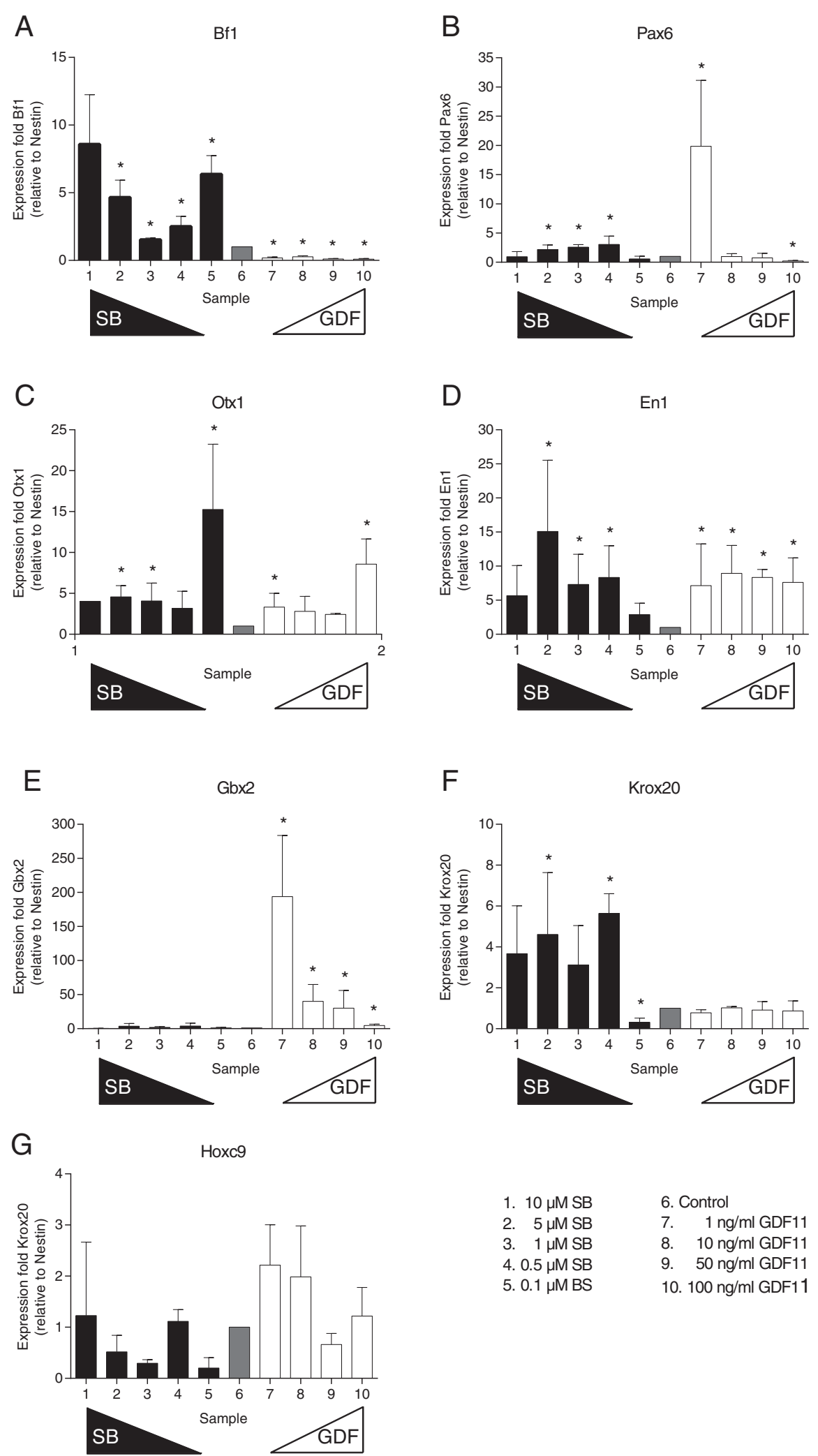

1. $10 \mu \mathrm{M} \mathrm{SB}$

2. $5 \mu \mathrm{M} \mathrm{SB}$

3. $1 \mu \mathrm{M} \mathrm{SB}$

4. $0.5 \mu \mathrm{M} \mathrm{SB}$

5. $0.1 \mu \mathrm{MBS}$
6. Control

7. $1 \mathrm{ng} / \mathrm{ml} \mathrm{GDF11}$

8. $10 \mathrm{ng} / \mathrm{ml}$ GDF11

9. $50 \mathrm{ng} / \mathrm{ml}$ GDF11

10. $100 \mathrm{ng} / \mathrm{ml} \mathrm{GDF11}$

Figure 1 (See legend on next page.) 
WI) and qRT-PCR was performed according to the method of Willems et al. [31].

Primer sequences for all markers used are available in the Real-Time Primer Database (http://medgen.ugent. be/rtprimerdb/). Expression levels were calculated as described using $A c t b$ as a reference gene [31]. In addition, expression levels of all regional marker genes were divided by the expression level of the panneural marker Nestin to correct for possible effects on neural differentiation [11].

Normalized expression levels of the treated samples were then calculated relatively to the expression levels of the corresponding untreated control, which was put at level one. The results are presented as the means of three independent experiments with the standard error of the mean. Statistical analysis was performed using a non-parametric test for comparing two groups (Mann Whitney). Statistically significant changes $(\mathrm{p}<0.05)$ are marked with an asterisk in the graphs, as compared to control (sample 6).

\section{Findings}

We developed a system to study early neural patterning and showed that Fgf2, Wnt3a and Bmp4 have a strong posteriorizing effect on neural differentiated $\mathrm{mESc}$, similar to what was also described to be the case in Xenopus $[1,2,11]$.

Analyses of the patterning potential of GDF11 showed that the addition of this factor induces a strong decrease of the anteriormost marker $B f 1$, and a significant upregulation of the intermediate markers Otx1, En1 and Gbx2 (Figure 1, panel A,C-E). On the posteriormost markers Krox20 and Hoxc9, no effect was seen (Figure 1, panel F-G). The effect on the diencephalic marker Pax6 was not unambiguous since at the lowest concentration tested, an increase was observed, while at the highest concentration tested, a decrease of Pax6 expression was induced (Figure 1, panel B). Next, Pax6 is expressed in neuroprogenitors in the developing spinal cord and not an exclusively in the diencephalon. This may contribute to the ambiguous results.

Treatment of the cells with SB431542 on the other hand, caused a significant upregulation of anterior markers like Bf1 and Otx1, while at most of the concentrations tested, a downregulation of Hoxc9 expression could be observed (Figure 1, panel A, C and G). This anteriorization indicates that endogenous posteriorization factors are actively signalling through the receptors blocked by SB431542.
GDF11 could indeed contribute to the endogenous patterning of the cells that could be inhibited by SB431542, since its expression, as well as the expression of the Alk4 and Alk5 type I receptors could be detected in the control cultures by qRT-PCR (data not shown).

In all gene expression data tested above, the expression levels of all regional markers (see Figure 2 for schematic diagram) were put relative to the expression level of the panneural marker Nestin in order to correct for possible inhibitory effects of the patterning factors tested on neural induction. Though in our experimental set-up, the neural induction process was separated in time from the neural patterning process, an inhibitory effect on Nestin expression could be seen by GDF11 treatment. Flow cytometric analysis was used to assess the percentage of Nestin-positive cells after treatment with these factors. Treatment of the cells with the highest concentrations of GDF11 reduced the number of Nestin-positive cells by $20 \%$ respectively. This indicates that in our experimental set up the inhibitory effect of GDF11 is limited, but could not completely be avoided. Therefore we corrected all expression data for the expression level of Nestin. These data indicate that GDF11 exerts a fundamental role during neural development.

\section{Discussion}

Though a neural patterning role is well established for Activin in Xenopus and in Zebrafish [33,34], we did not detect any posteriorizing effect by recombinant Activin A in our mES cell based patterning system (data not shown). Nodal, well known for its crucial role in the establishment of the A/P body axis, was the next candidate we tested. More precisely, the Nodal antagonists Lefty1 and Cerberus-like that are expressed in the anterior visceral endoderm (AVE) of the mouse embryo, are essential for the anterior neural specification $[35,36]$. Whether Nodal itself can posteriorize the neural tissue in the mouse has not directly been shown and addition of recombinant Nodal to the neural precursor cells in our system did not directly induce any posteriorization either (data not shown).

Since SB431542 was tested and shown to affect A/P patterning of the brain, we searched for other candidates like Nodal or Activin that could signal via the Alk systems blocked by SB431542.

Several GDFs (GDF1, GDF3, GDF8, GDF9 and GDF11) were shown to signal through the Alk4, Alk5 or the Alk7 receptor [22,37-40]. GDF11 was shown to signal preferentially 


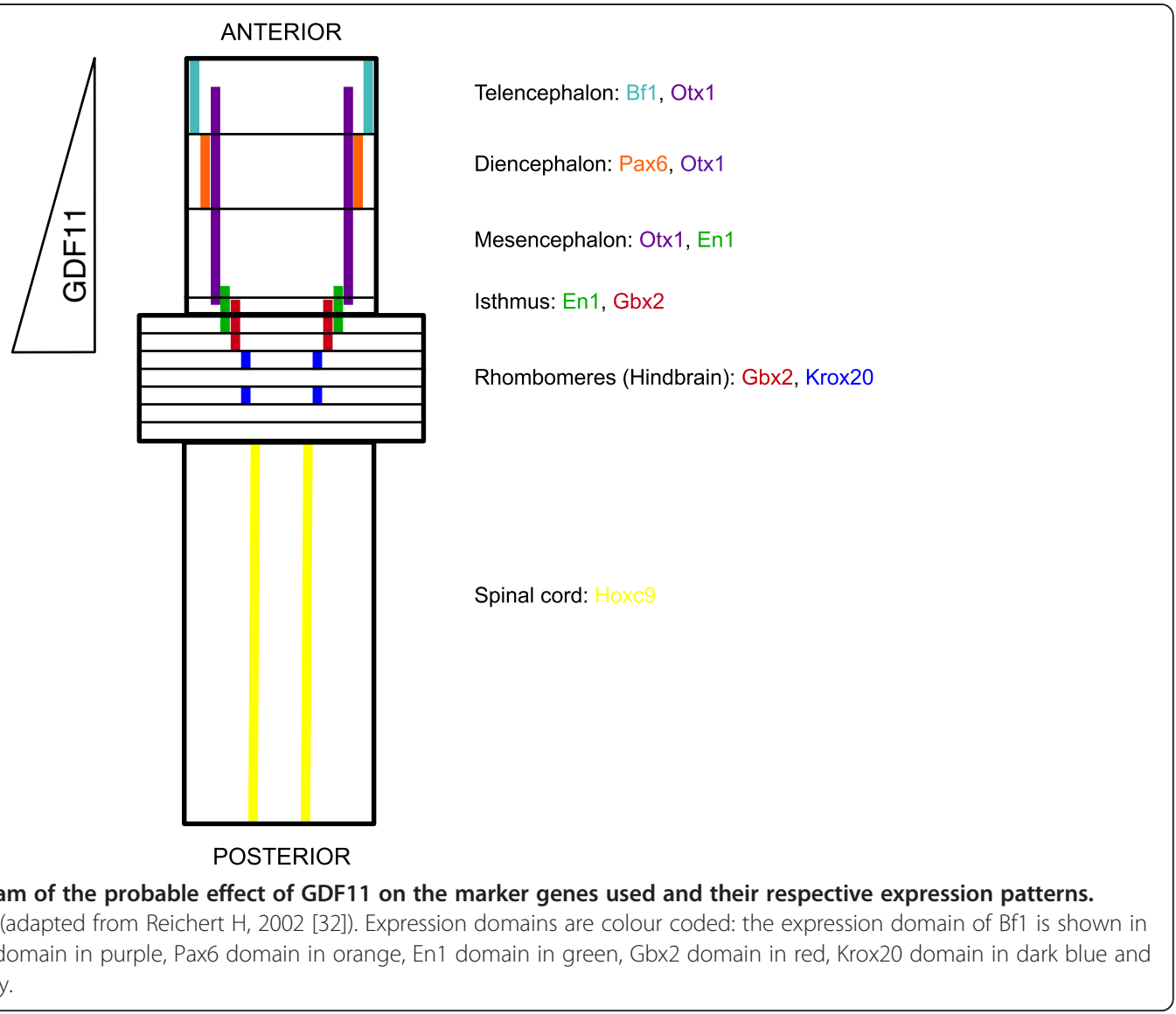

through the Alk5 receptor and has been implicated in the establishment of the skeletal pattern [22,27]. Whether this factor also has an effect on the regionalization of the mouse neural tube remained elusive. In chick however, overexpression of GDF11 in the neural tube caused a rostral displacement of the Hox expression domains and the motor neuron columns [28]. During the present study, we investigated whether GDF11 has a direct role in the early regional identity of neural progenitor cells and whether this factor can posteriorize freshly induced neural progenitors that are initially anterior in character. The potential neural patterning effect of GDF11 was assessed in our ES cell based patterning system.

GDF11 was indeed shown to be a strong patterning factor, reducing the expression levels of the most anterior markers $B f 1$ (ventral telencephalon) and upregulating the expression of more posterior neural markers like En1 (isthmus, midbrain to midbrain-hindbrain junction) and $G b \times 2$ (hindbrain). The most posterior marker, Hoxc9 (neural tube), tested remained unaffected, indicating that the role of GDF11 is limited to the developing brain. More specifically, GDF11 induces midbrain and anterior hindbrain fates at the expense of telencephalic fates. This is the first time that this factor is implicated in the regionalization of the brain during early mouse development, where GDF11 could play a more permissive or maintenance role for the expansion of certain progenitors (i.e. Otx1+, En1+ progenitors). Furthermore, the presence of GDF11, Alk4 and Alk5 mRNAs in the differentiated ES cells indicates that GDF11 may be endogenously signalling in our system. However, the observed effect for GDF11 was not completely opposite to the one observed by adding SB431542, for example both GDF11 and SB431542 caused a significant upregulation of anterior marker Otx1 (forebrain, but not most rostral part, and midbrain), as compared to the opposite effect observed on Bf1. SB431542 might exert a pleiotophic effect, inhibiting Alk4, Alk5 as well as Alk7 $[41,42]$. This suggests that other TGF- $\beta$ factors signalling through these receptors (including other GDFs), may have an additional patterning function in the developing neural tube and that SB431542 inhibits all of these effects. This still needs further investigation.

Because of this clear regionalizing effect of GDF11, we also tested Follistatin, a GDF11 antagonist, for its patterning potential, but no significant changes in the expression levels of the regional markers could be observed (data not shown). It might be possible that, blocking receptors by pharmalogical inhibitors, such as SB431542, is more efficient than the addition of proteins antagonizing the signalling factor because of the long experimental culture period. 
At the developmental stage where the early regionalization of the neural tube and encephalic region is established, GDF11 was predominantly expressed in the posterior spinal cord. This expression pattern was not fully compatible with the observed encephalic regionalization effect, since this was restricted anteriorly to the level of the hindbrain. However, GDF11 expression was also detected in the brain region by using the radioactive in situ hybridization technique [30]. Our results suggest a localized activity of GDF11 in the metencephalic region of the brain but how this regional activity in the posterior encephalic region of GDF11 is established, remains unclear. Future research is needed to determine if GDF11 is acting together with another signalling molecule, possibly another member of the TGF- $\beta$ superfamily or if localized, possibly graded, GDF11 signalling inhibitors are involved in the patterning effect observed. Finally, it should be noted that the regionalization by GDF11 is not a typical posteriorizing signal as seen with retinoic acid, FGF or BMP molecules since these also lead to an increase of more posterior markers while GDF11 is an encephalic regionalizing factor.

\section{Competing interests}

The authors declare that they have no competing interests.

\section{Authors' contributions}

NV carried out the whole mount in situ hybridization experiments (data not shown, Ethical approval was obtained from "Ethical committee for animal experiments from the Vrije Universiteit Brussel", Ethical no. 04-220-4, 03-220-3), qRT-PCR, data analysis and drafted the manuscript. MH designed the study, performed the cell culture experiments, data analysis and drafted the manuscript. LL supervised the study design and reviewed the paper. All authors read and approved the final manuscript.

\section{Acknowledgements}

The laboratory is supported by the Research Foundation Flanders (FWO) (Grant G.0485.06), the EU (6 ${ }^{\text {th }}$ Framework, Grant NEST012930) and the Belgian Science Policy Office (IUAP P7/07 DevRepair). M.H. was supported as an FWO aspirant. We would also like to thank the laboratory for Cellular and Molecular Immunology (VUB) for the use of their flow cytometry facility.

\section{Grants}

Research Foundation-Flanders (FWO): G.0485.06 and the EU: $6^{\text {th }}$ Framework NEST012930 and InterUniversity Attraction Pole: P7/07 DevRepair.

\section{Author details}

${ }^{1}$ Department of Biology, Lab for Cell Genetics, Vrije Universiteit Brussel (VUB), 2 Pleinlaan, B-1050 Brussels, Belgium. ${ }^{2}$ Present address: The Belgian Scientific Institute for Public Health (WIV-ISP), Communicable and infectious diseases, Mycology and aerobiology, 14 J. Wytsmanstraat, B-1050 Brussels, Belgium.

Received: 13 February 2014 Accepted: 14 October 2014

Published: 29 October 2014

\section{References}

1. Levine AJ, Brivanlou AH: Proposal of a model of mammalian neural induction. Dev Biol 2007, 308:247-256.

2. Sakai M: Cell-autonomous and inductive processes among three embryonic domains control dorsal-ventral and anterior-posterior development of Xenopus laevis. Dev Growth Differ 2008, 50:49-62.

3. Sasai $Y$, De Robertis EM: Ectodermal patterning in vertebrate embryos. Dev Biol 1997, 182:5-20.
4. Cox WG, Hemmati-Brivanlou A: Caudalization of neural fate by tissue recombination and bFGF. Development 1995, 121:4349-4358.

5. Domingos PM, Itasaki N, Jones CM, Mercurio S, Sargent MG, Smith JC, Krumlauf R: The Wnt/beta-catenin pathway posteriorizes neural tissue in Xenopus by an indirect mechanism requiring FGF signalling. Dev Biol 2001, 239:148-160.

6. Kiecker C, Niehrs C: A morphogen gradient of Wnt/beta-catenin signalling regulates anteroposterior neural patterning in Xenopus. Development 2001, 128:4189-4201.

7. McGrew LL, Hoppler S, Moon RT: Wnt and FGF pathways cooperatively pattern anteroposterior neural ectoderm in Xenopus. Mech Dev 1997, 69:105-114.

8. Monsoro-Burq AH, Fletcher RB, Harland RM: Neural crest induction by paraxial mesoderm in Xenopus embryos requires FGF signals. Development 2003, 130:3111-3124.

9. De Miguel MP, Fuentes-Julian S, Alcaina Y: Pluripotent stem cells: origin, maintenance and induction. Stem Cell Rev 2010, 6:633-649.

10. Smith AG: Embryo-derived stem cells: of mice and men. Annu Rev Cell Dev Biol 2001, 17:435-462.

11. Hendrickx M, Van XH, Leyns L: Anterior-posterior patterning of neural differentiated embryonic stem cells by canonical Wnts, Fgfs, Bmp4 and their respective antagonists. Dev Growth Differ 2009, 51:687-698.

12. Ying QL, Stavridis M, Griffiths D, Li M, Smith A: Conversion of embryonic stem cells into neuroectodermal precursors in adherent monoculture. Nat Biotechnol 2003, 21:183-186.

13. Bouhon IA, Kato H, Chandran S, Allen ND: Neural differentiation of mouse embryonic stem cells in chemically defined medium. Brain Res Bull 2005, 68:62-75.

14. Garcia-Morales C, Liu CH, Abu-Elmagd M, Hajihosseini MK, Wheeler GN: Frizzled-10 promotes sensory neuron development in Xenopus embryos. Dev Biol 2009, 335:143-155.

15. Haegele L, Ingold B, Naumann H, Tabatabai G, Ledermann B, Brandner S: Wnt signalling inhibits neural differentiation of embryonic stem cells by controlling bone morphogenetic protein expression. Mol Cell Neurosci 2003, 24:696-708.

16. Ogawa K, Nishinakamura R, Iwamatsu Y, Shimosato D, Niwa H: Synergistic action of Wnt and LIF in maintaining pluripotency of mouse ES cells. Biochem Biophys Res Commun 2006, 343:159-166.

17. Sato N, Meijer L, Skaltsounis L, Greengard P, Brivanlou AH: Maintenance of pluripotency in human and mouse embryonic stem cells through activation of Wnt signaling by a pharmacological GSK-3-specific inhibitor. Nat Med 2004, 10:55-63.

18. Ying QL, Nichols J, Chambers I, Smith A: BMP induction of Id proteins suppresses differentiation and sustains embryonic stem cell self-renewal in collaboration with STAT3. Cell 2003, 115:281-292.

19. Shi Y, Massague J: Mechanisms of TGF-beta signaling from cell membrane to the nucleus. Cell 2003, 113:685-700.

20. Wharton K, Derynck R: TGFbeta family signaling: novel insights in development and disease. Development 2009, 136:3691-3697.

21. Wu MY, Hill CS: Tgf-beta superfamily signaling in embryonic development and homeostasis. Dev Cell 2009, 16:329-343.

22. Andersson O, Reissmann E, Ibanez CF: Growth differentiation factor 11 signals through the transforming growth factor-beta receptor ALK5 to regionalize the anterior-posterior axis. EMBO Rep 2006, 7:831-837.

23. Dichmann DS, Yassin H, Serup P: Analysis of pancreatic endocrine development in GDF11-deficient mice. Dev Dyn 2006, 235:3016-3025.

24. Esquela AF, Lee SJ: Regulation of metanephric kidney development by growth/differentiation factor 11. Dev Biol 2003, 257:356-370.

25. Gamer LW, Wolfman NM, Celeste AJ, Hattersley G, Hewick R, Rosen V: A novel BMP expressed in developing mouse limb, spinal cord, and tail bud is a potent mesoderm inducer in Xenopus embryos. Dev Biol 1999, 208:222-232.

26. Li Z, Kawasumi M, Zhao B, Moisyadi S, Yang J: Transgenic over-expression of growth differentiation factor 11 propeptide in skeleton results in transformation of the seventh cervical vertebra into a thoracic vertebra. Mol Reprod Dev 2010, 77:990-997.

27. McPherron AC, Lawler AM, Lee SJ: Regulation of anterior/posterior patterning of the axial skeleton by growth/differentiation factor 11 . Nat Genet 1999, 22:260-264.

28. Liu JP: The function of growth/differentiation factor 11 (Gdf11) in rostrocaudal patterning of the developing spinal cord. Development 2006, 133:2865-2874. 
29. Nakashima M, Toyono T, Akamine A, Joyner A: Expression of growth/ differentiation factor 11, a new member of the BMP/TGFbeta superfamily during mouse embryogenesis. Mech Dev 1999, 80:185-189.

30. Essalmani R, Zaid A, Marcinkiewicz J, Chamberland A, Pasquato A, Seidah $N G$, Prat A: In vivo functions of the proprotein convertase PC5/6 during mouse development: Gdf11 is a likely substrate. Proc Natl Acad Sci U S A 2008, 105:5750-5755.

31. Willems E, Mateizel I, Kemp C, Cauffman G, Sermon K, Leyns L: Selection of reference genes in mouse embryos and in differentiating human and mouse ES cells. Int J Dev Biol 2006, 50:627-635.

32. Reichert $\mathrm{H}$ : Conserved genetic mechanisms for embryonic brain patterning. Int J Dev Biol 2002, 46:81-87.

33. Green JB, Cook TL, Smith JC, Grainger RM: Anteroposterior neural tissue specification by activin-induced mesoderm. Proc Natl Acad Sci U S A 1997, 94:8596-8601

34. Thisse B, Wright CV, Thisse C: Activin- and Nodal-related factors control antero-posterior patterning of the zebrafish embryo. Nature 2000 403:425-428.

35. Perea-Gomez A, Vella FD, Shawlot W, Oulad-Abdelghani M, Chazaud C Meno C, Pfister V, Chen L, Robertson E, Hamada H, Behringer RR, Ang SL: Nodal antagonists in the anterior visceral endoderm prevent the formation of multiple primitive streaks. Dev Cell 2002, 3:745-756.

36. Yamamoto M, Saijoh Y, Perea-Gomez A, Shawlot W, Behringer RR, Ang SL, Hamada H, Meno C: Nodal antagonists regulate formation of the anteroposterior axis of the mouse embryo. Nature 2004, 428:387-392.

37. Rebbapragada A, Benchabane H, Wrana JL, Celeste AJ, Attisano L: Myostatin signals through a transforming growth factor beta-like signaling pathway to block adipogenesis. Mol Cell Biol 2003, 23:7230-7242.

38. Mazerbourg S, Klein C, Roh J, Kaivo-Oja N, Mottershead DG, Korchynskyi O, Ritvos O, Hsueh AJ: Growth differentiation factor-9 signaling is mediated by the type I receptor, activin receptor-like kinase 5. Mol Endocrinol 2004, 18:653-665.

39. Andersson $\mathrm{O}$, Bertolino $\mathrm{P}$, Ibanez CF: Distinct and cooperative roles of mammalian Vg1 homologs GDF1 and GDF3 during early embryonic development. Dev Biol 2007, 311:500-511.

40. Andersson O, Reissmann E, Jornvall H, Ibanez CF: Synergistic interaction between Gdf1 and Nodal during anterior axis development. Dev Biol 2006, 293:370-381.

41. Inman GJ, Nicolas FJ, Callahan JF, Harling JD, Gaster LM, Reith AD, Laping NJ, Hill CS: SB-431542 is a potent and specific inhibitor of transforming growth factor-beta superfamily type I activin receptor-like kinase (ALK) receptors ALK4, ALK5, and ALK7. Mol Pharmacol 2002, 62:65-74.

42. Ogunjimi AA, Zeqiraj E, Ceccarelli DF, Sicheri F, Wrana JL, David L: Structural basis for specificity of TGFbeta family receptor small molecule inhibitors. Cell Signal 2012, 24:476-483.

doi:10.1186/1756-0500-7-766

Cite this article as: Vanbekbergen et al:: Growth differentiation Factor 11 is an encephalic regionalizing factor in neural differentiated mouse embryonic stem cells. BMC Research Notes 2014 7:766.

\section{Submit your next manuscript to BioMed Central and take full advantage of:}

- Convenient online submission

- Thorough peer review

- No space constraints or color figure charges

- Immediate publication on acceptance

- Inclusion in PubMed, CAS, Scopus and Google Scholar

- Research which is freely available for redistribution 